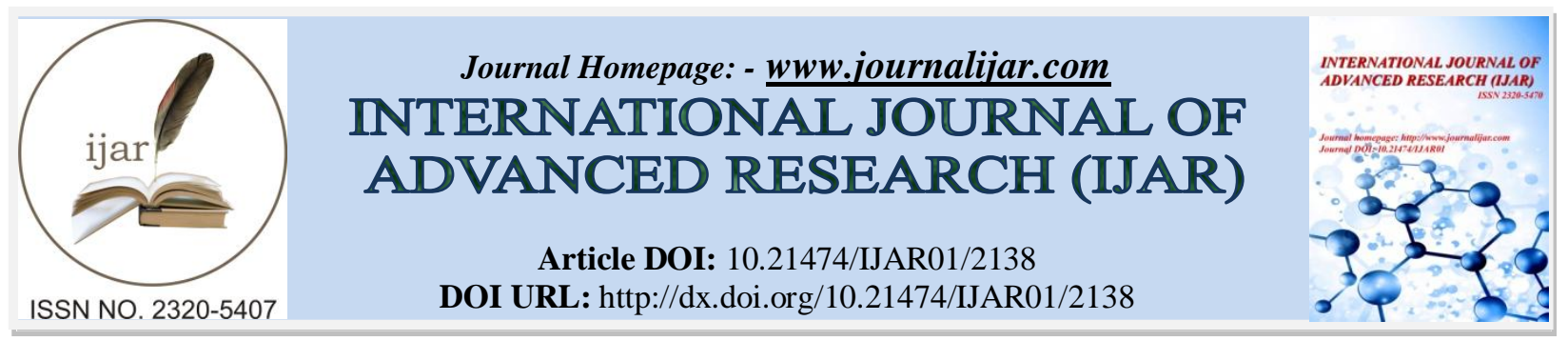

RESEARCH ARTICLE

\title{
MICROMETRY FOR DIFFERENTIATION OF DEMODEX MITE SPECIES CAUSING CANINE DEMODICOSIS IN INDIA
}

\author{
B.Swathi", S. Ayodhya and K. Satishkumar.
}

Pv Narsimha Rao Veterinary Nniversity, Rajendranagar, Hyderabad, Telangana, India.

\section{Manuscript Info}

Manuscript History

Received: 25 September 2016

Final Accepted: 27 October 2016

Published: November 2016

Key words:-

canine demodicosis-micrometry-

Demodex canis, Demodex cornei,

Demodex injai

\section{Abstract}

In the present clinical study, the dog mites of Demodex species were differentiated based on their morphology and morphometrics. Micrometry was done using ocular and stage micrometers. Demodex canis was characterized by its cigar shape with mean body length 217 $\pm 2.39 \mu \mathrm{m}$, Demodex cornei which were short, stumpy measured $138.99 \pm 3.21 \mu \mathrm{m}$ and elongated mites Demodex injai $264 \pm 6.89 \mu \mathrm{m}$. The three Demodex species differed significantly in their morphology and parameters viz., opisthosoma length, ratio of prosoma to opisthosoma and ratio of mean total bodylength and opisthosoma length. Hence, these mite species can easily be differentiated by using these morphometric parameters.

Copy Right, IJAR, 2016,. All rights reserved.

\section{Introduction:-}

Canine demodicosis can be diagnosed by identifying mites in skin samples. There are three species of Demodex mites with different location and consequently, with different courses and varied symptoms in dogs (Sakulpoy and Sangvaranond, 2010). Demodex canis which lives in hair follicles causes demodectic folliculitis and/ or furunculosis in dogs; $D$. injai inhabits in pilosebaceous glands induces oily skin and hair coat on trunk of dogs; however, $D$. cornei can cause a pruritic canine skin disease by inhabiting in stratum corneum.

Follicular mite, Demodex canis is the most common species and there have been two other morphologically different types of Demodex mites named as Demodex cornei and Demodex injai being reported in different countries in the recent past (Sivajothiet al., 2013a).Morphometric studies were useful in differentiation of Demodex species were less in India. Hence, the present study of micrometry was undertaken to record the morphometry of Demodex mites, i.e. D.canis, D. cornei and D. injai in dogs with demodicosis.

\section{Materials and methods:-}

Skin samples were taken from 20 dogs suffering from demodicosis, which were presented to Teaching Veterinary Clinical Complex (TVCC), College of Veterinary Science, Rajendranagar,Hyderabad. The skin samples thus collected using deep skin scrapings, tape impression smears and hair plucks were processed using $10 \% \mathrm{KOH}$ (Soulsby, 2005) and were preserved in 70\% ethanol till micrometry was done. Micrometry was performed by using ocular and stage micrometers under compound microscope (Sriraman, 2006) for measuring mites, after calibration under 40X magnification (Figure 1). 
Figure 1:- Calibration of ocular and stage micrometers under 40X magnification

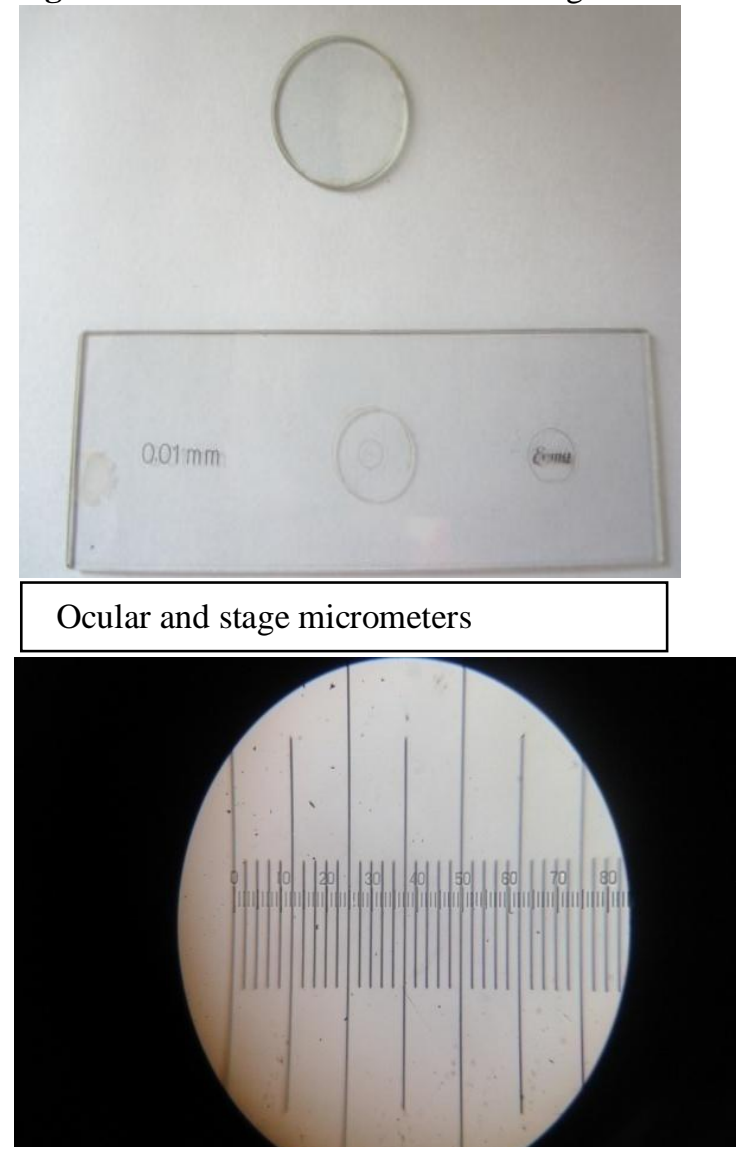

Calibrations with micrometers under 40X.

Smears of processed skin samples were used for morphological studies and measurements of the Demodex mites were made. Total of 179 mites were measured using calibrated micrometers $(\mu \mathrm{m})$ and mean body length $(\mu \mathrm{m})$, mean lengths $(\mu \mathrm{m})$ of gnathosoma,podosoma and opisthosoma, mean width $(\mu \mathrm{m})$ of gnathosoma, podosoma and opisthosoma, ratio of prosoma to opisthosoma, ratio of total body length and opisthosoma length, ratio of length opisthosoma length to bodylength (\%) and the mean length and mean width of Demodex mite eggs were measured.

\section{Results and Discussion:-}

Using micrometry analysis, among the skin samples collected from 20 Demodex positive dogs, 19 dogs were positive for Demodex canis, among them synhospitalic mite infestation with Demodex canis and Demodex cornei were noted in $40 \%$ (8) dogs. Demodex injai was identified in the skin samples taken from one dog with generalized demodicosis.

The morphometrics of three Demodex species were presented in table 1 and the micrometry of Demodex mites and their eggs shown in figure 2. 
Figure 2:- Micrometry of Demodex mites and their eggs.
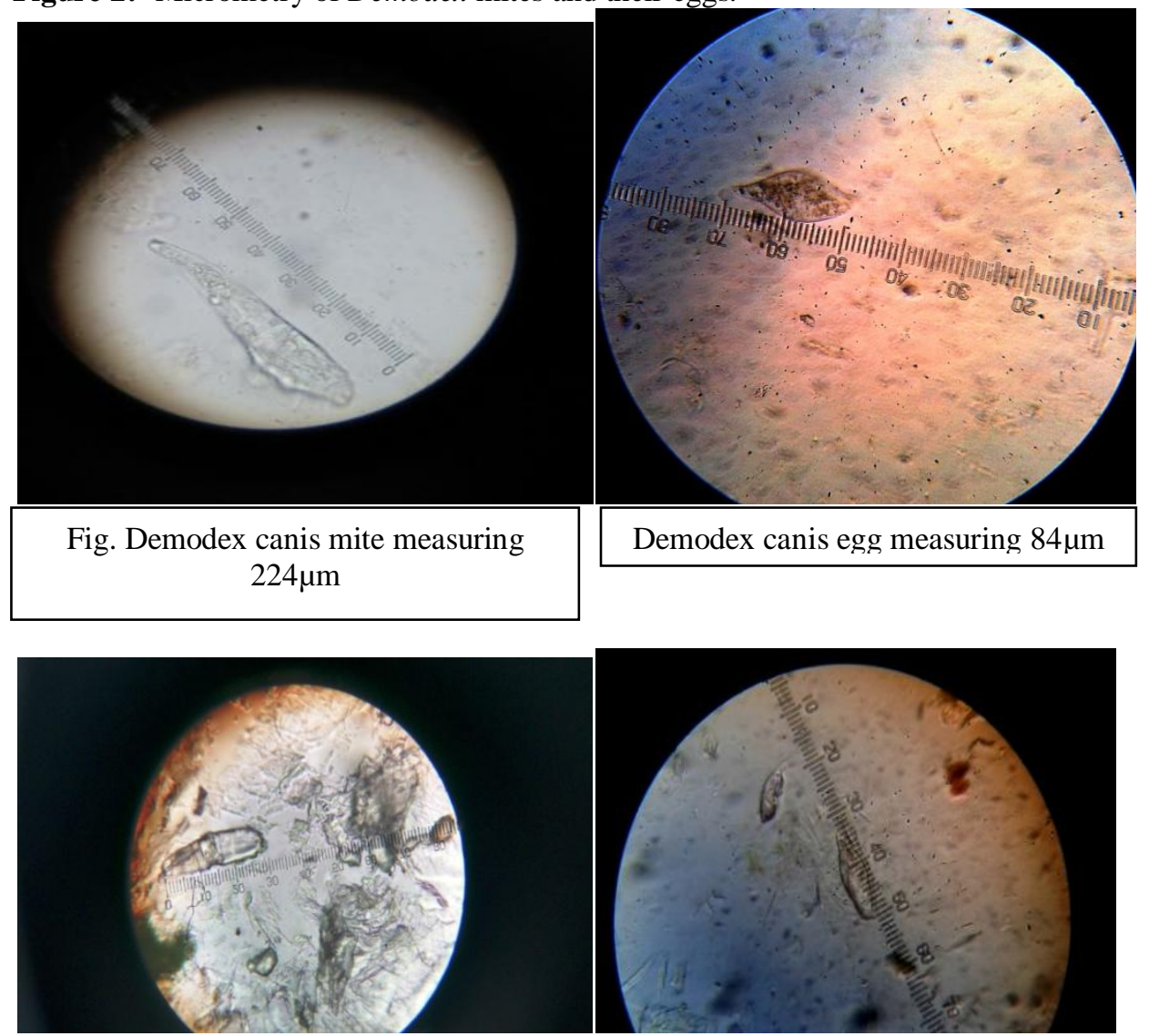

Demodex cornei mite measuring $120 \mu \mathrm{m}$

Demodex cornei egg measuring $68 \mu \mathrm{m}$

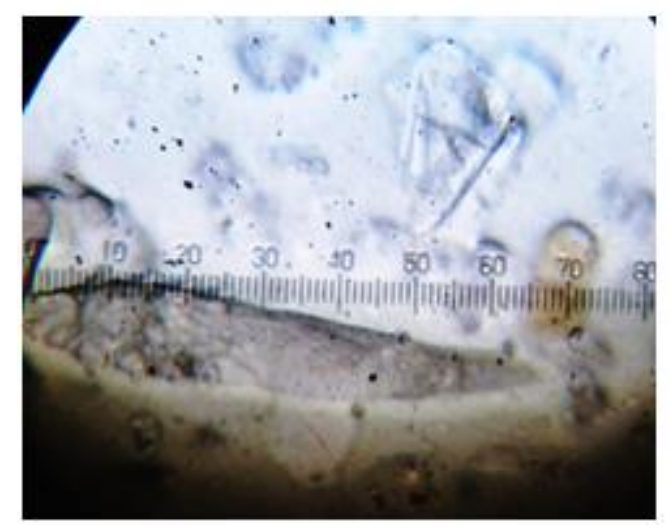

Demodex injai mite measuring about $264 \mu \mathrm{m}$

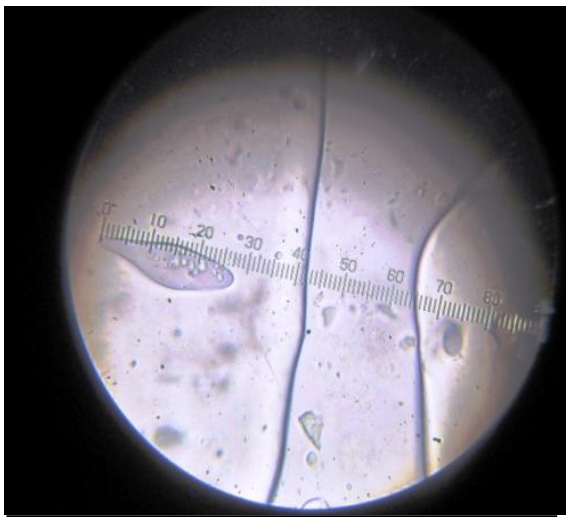

Demodex injai egg measuring $108 \mu \mathrm{m}$ 
Table 1:- The morphometrics of three Demodex species.

\begin{tabular}{|c|c|c|c|c|c|}
\hline S. No. & \multicolumn{2}{|l|}{ Parameters } & D.canis $(\mathrm{n}=98)$ & D.cornei $(\mathrm{n}=52)$ & D.injai $(\mathrm{n}=29)$ \\
\hline \multirow[t]{2}{*}{1} & \multirow[t]{2}{*}{ Gnathosoma $(\mu \mathrm{m})$} & Length & $23.1 \pm 0.33$ & $18.2 \pm 0.6$ & $23.65 \pm 0.69$ \\
\hline & & Width & $25.6 \pm 0.7$ & $17.6 \pm 0.65$ & $24.03 \pm 1.05$ \\
\hline \multirow[t]{2}{*}{2} & \multirow[t]{2}{*}{ Podosoma $(\mu \mathrm{m})$} & Length & $64.16 \pm 0.73$ & $58.5 \pm 1.86$ & $74.31 \pm 1.36$ \\
\hline & & Width & $40.71 \pm 0.41$ & $36 \pm 3.3$ & $42.72 \pm 0.86$ \\
\hline \multirow[t]{2}{*}{3} & \multirow[t]{2}{*}{ Opisthosoma* $(\mu \mathrm{m})$} & Length & $135.59 \pm 3.17$ & $80.84 \pm 7.33$ & $168.6 \pm 7.78$ \\
\hline & & Width & $36.2 \pm 0.98$ & $25.71 \pm 2.6$ & $32.35 \pm 0.49$ \\
\hline 4 & Total body length ${ }^{*}(\mu \mathrm{m})$ & & $217 \pm 2.39$ & $138.99 \pm 3.21$ & $264 \pm 6.89$ \\
\hline \multirow[t]{2}{*}{5} & \multirow[t]{2}{*}{$\operatorname{Egg}(\mu \mathrm{m})^{*}$} & Length & $82.3 \pm 3.96$ & $69 \pm 4.12$ & $105.5 \pm 3.36$ \\
\hline & & Width & $23.5 \pm 0.99$ & $21.6 \pm 1.26$ & $28.4 \pm 1.03$ \\
\hline 6 & $\begin{array}{l}\text { Ratio of prosoma to } \\
\text { opisthosoma* }\end{array}$ & & $0.65 \pm 0.02$ & $1.26 \pm 0.02$ & $0.56 \pm 0.03$ \\
\hline 7 & $\begin{array}{l}\text { Ratio of mean total } \\
\text { bodylength } \\
\text { opisthosoma length* }\end{array}$ & & 1.64 & 2.05 & 1.57 \\
\hline 8 & $\begin{array}{l}\text { Ratio of opisthosoma } \\
\text { length to bodylength } \\
(\%)^{*}\end{array}$ & & 57.96 & 48.54 & 63.69 \\
\hline
\end{tabular}

* Significant $(\mathrm{P}<0.05)$

The mean total body length of Demodex canis $(217 \pm 2.39 \mu \mathrm{m})$ was almost agreable with the findings of Tamura et al (2001), Sakulpoy and Sangvaranond (2010), Sivajothi et al (2013a) and Sivajothi et al (2013b), who had reported mean body lengths of Demodex canis as $229 \pm 35.1,217.83 \pm 30.06,211.81 \pm 14.86$ and $214.32 \pm 13.81 \mu \mathrm{m}$, respectively.

The mean lengths $(\mu \mathrm{m})$ of gnathosoma, podosoma and opisthosoma of Demodex canis reported in the present study were $23.1 \pm 0.33,64.16 \pm 0.73,135.59 \pm 3.17$, respectively, were coinciding with the findings of Tamura et al. (2001), who reported 18.9- 24.4, $94.11 \pm 8.4$ and $136.6 \pm 18.5 \mu \mathrm{m}$, Sakulpoy and Sangvaranond (2010) reported (mean \pm SD) $24.84 \pm 1.70,60.89 \pm 2.10 \mu \mathrm{m}$ and $147.50 \pm 19.56 \mu \mathrm{m}$, Sivajothi et al. (2013a) $19.52 \pm 0.10,62.68 \pm$ $0.33 \mu \mathrm{m}$ and $130.52 \pm 2.47 \mu \mathrm{m}$ and Sivajothi et al. (2013b) $18.89 \pm 0.18,60.98 \pm 0.21$, and $129.68 \pm 3.3 \mu \mathrm{m}$, respectively.

The mean width $(\mu \mathrm{m})$ of gnathosoma, podosoma and opisthosoma of Demodex canis were 25.6 $\pm 0.7,40.71 \pm 0.41$, and $36.2 \pm 0.98$ were comparable with the reports of Tamura et al. (2001), who documented measurements of gnathosoma width 18.9-20 $\mu \mathrm{m}$, and opisthosoma width 26.5 $\pm 4.2 \mu \mathrm{m}$ using scanning electron microscopy (SEM).

The ratio of prosoma to opisthosoma was $0.65 \pm 0.02$; which was similar to the reports of Sivajothi et al. (2013a), who reported the ratio as $0.62 \pm 0.02$ for Demodex canis.

The ratio of mean total body length and opisthosoma length was 1.64 , which was closer to the findings of Sakulpoy and Sangvaranond (2010), who reported the ratio as 1.39 , the difference could be due to more variations in lengths of opisthosoma of $D$. canis mites of the study undertaken.

Ratio of opisthosoma length to total body length in Demodex canis was found to be $57.96 \%$, which coincided with the findings of Izdebska (2010), who found this parameter in D. canis (51 in males, 59 in females) lesser than that of D.injai and greater than that of D.cornei.

The mean length and mean width of Demodex canis eggs found in the present study were $82.3 \pm 3.96$ and $23.5 \pm$ $0.99 \mu \mathrm{m}$, respectively, which coincided with the reports of Nutting and Desch (1978), who documented $81.5 \pm 3.5$ and $26.6 \pm 2.4$ egg length and width of Demodex canis, respectively.

The mean body length $(\mu \mathrm{m})$ of Demodexcornei in the present study $138.99 \pm 3.21(95.90-164.4)$ was matched with the reports of Tamura et al. (2000), who reported 97.5-167.5 (139) $\mu$ m mean body length of Demodex cornei, and Tamura et al. (2001), who reported $139 \pm 21.6 \mu \mathrm{m}$, Sakulpoy and Sangvaranond (2010) found 156.92 $\mu \mathrm{m}$, Lopez et 
al. (2011) documented 139.3 \pm 10.4 , Sivajothi et al. (2013a) as $137.15 \pm 22.84 \mu \mathrm{m}$ and Sivajothi et al. (2013b), who reported mean body lengths of Demodex canis $132.21 \pm 14.6 \mu \mathrm{m}$.

The mean lengths $(\mu \mathrm{m})$ of gnathosoma, podosoma and opisthosoma of Demodex cornei in the present study were $18.2 \pm 0.596,58.5 \pm 1.86$, and $80.84 \pm 7.33$ respectively, which were similar to the findings of Tamura et al. (2001), who reported the lengths of gnathosoma, leg region of proterosoma and opisthosoma of D. cornei 14-21.4, 13.0 and $31.5 \pm 6.2 \mu \mathrm{m}$, Sakulpoy and Sangvaranond (2010) reported in microns \pm SD $23.50 \pm 1.93,60.00 \pm 2.50$ and $59.25 \pm$ 9.68, respectively. Lopez et al. (2011) documented gnathosoma, podosoma and opisthosoma length of D.cornei ranged from 18 to $25 \mu \mathrm{m}(21.9 \pm 2.2), 52$ to $68 \mu \mathrm{m}(61.2 \pm 4.6)$ and 48 to $69 \mu \mathrm{m}(56.2 \pm 8.4)$, respectively.

The mean width $(\mu \mathrm{m})$ of gnathosoma, podosoma and opisthosoma of Demodex cornei were $17.6 \pm 0.65,36 \pm 3.3$, $25.71 \pm 2.597$ respectively, which was similar to the findings of Lopez et al. (2011), who reported Gnathosoma, podosoma and opisthosoma width of Demodex cornei ranged from 18 to $28 \mu \mathrm{m}(20.6 \pm 2.3), 29$ to $44 \mu \mathrm{m}(33.5 \pm$ $5.6)$ and 26 to $35 \mu \mathrm{m}(29.9 \pm 2.6)$, respectively.

The ratio of prosoma to opisthosoma was $1.26 \pm 0.02$, which was similar to the reports of Sivajothi et al. (2013a), who reported the ratio as $1.37 \pm 0.04$ for Demodex cornei.

The ratio of mean total body length and opisthosoma length was 2.05, which was closer to the reports of Sakulpoy and Sangvaranond (2010), who reported 2.49. The difference could be due to more variations in lengths of opisthosoma of $D$. cornei mites of the study undertaken.

Ratio of opisthosoma length to total body length in Demodex cornei was found to be $48.54 \%$, which is coincide with the findings of Izdebska (2010), who found this parameter in D. cornei very much less than that of Demodex canis and Demodex injai .

The mean length $(\mu \mathrm{m})$ and mean width $(\mu \mathrm{m})$ of Demodex cornei eggs were $69 \pm 4.12$ and21.6 \pm 1.26 , respectively, which were matched with the findings of Lopez et al. (2011), who reported egg length and width $71.7 \pm 2.5$ (68 79) and $22.1 \pm 1.4(20-24)$ of Demodex cornei.

Mean body length of Demodex injai was found to be $264 \pm 6.89 \mu \mathrm{m}$, which was matched with lower limit reported by Hillier and Desch (2002), who documented Demodex injai mite body length 270-390 $\mu \mathrm{m}$, the difference may be due to small sample size with size variations.

The mean lengths $(\mu \mathrm{m})$ of gnathosoma, podosoma and opisthosoma were $23.65 \pm 0.69,74.31 \pm 1.36$, and $168.6 \pm$ 7.78 in Demodex injai of present study were similar to the findings of Hillier and Desch (2002), who reported $23.4 \pm$ $1.1,87.0 \pm 3.6$ and $225.4 \pm 29.1$, respectively.

The mean width $(\mu \mathrm{m})$ of gnathosoma, podosoma and opisthosoma of Demodex injai were $24.03 \pm 1.05,42.72 \pm 0.86$ and $32.35 \pm 0.49$ which matched with the findings of Hillier and Desch (2002), who reported $28.0 \pm 1.7,44.3 \pm 2.5$ and $35.6 \pm 2.9$, respectively.

The ratio of prosoma to opisthosoma and ratio of mean of total body length and opisthosoma length of $0.56 \pm 0.03$ and 1.57, respectively; which were lesser than other two species due to longer opisthosoma. The previous findings of authors were not available for these parameters.

The ratio of opisthosoma length to body length (\%) in Demodex injai mites was 63.69 which was more compared to other two species, matched with the findings of Izdebska (2010), who reported 68\% in Demodex injai, which was more than respective parameter in other two species of Demodex mites.

The mean length and mean width of Demodex injai eggs $(\mu \mathrm{m})$ were $105.5 \pm 3.36$ and $28.4 \pm 1.03$, respectively, which was almost in agreement with the findings of Hillier and Desch (2002), who reported the mean length and width of Demodex injai egg were $104.6 \pm 5.0$ and $29.93 \pm 1.9$, respectively. 


\section{References:-}

1. Alvarez L, Medina O C, Garcia M E and Garcia H (2007) First report of an unclassified Demodex mite causing demodicosis in a Venezuelan dog. Annals of Tropical Medicine and Parasitology. 101(6): 529-532

2. Chen C, Hou C C and Bourdeau P J (2002) Easy way to differentiate short-tailed demodectic mite from Demodex canis. Veterinary Dermatology: 211-229.

3. Izdebska J N (2010) Demodex spp. acari, demodecidae and demodecosis in dogs: characteristics, symptoms, occurrence.Bulletin of the Veterinary Institute in Pulawy. 54: 335-338.

4. Izdebska J N and Fryderyk S (2011) Diversity of three species of the genus Demodex parasitizing Dogs in Poland. Polish Journal of Environmental Studies. 20 (3): 565-569.

5. Lopez J R, Reyero R D and Banos N D (2011) First report of canine demodicosis by short bodied Demodex mite in Spain. RevistaIbero-Latinoamericana Parasitology. 70 (2):219-224.

6. Sakulploy R and Sangvaranond A (2010) Canine Demodicosis caused by Demodex canis and short opisthosomal Demodex cornei in Shi Tzu dog from Bangkok Metropolitan Thailand.Kasetsart Veterinarians.20(1).

7. Sivajothi S, Sudhakara B R and Rayulu V C (2013b) Demodicosis caused by Demodex canis and Demodexcorneiin dogs. Journal of Parasitic Diseases.

8. Sivajothi S, Sudhakara B R, Kumari N K and Rayulu V C (2013a) Morphometry of Demodex canis and Demodexcorneïn Dogs with Demodicosis in India, International Journal of Veterinary Health Science and Research. 01(02): 06-08.

9. Soulsby E J L, 2005 Helminths, Arthropods and Protozoa of domesticated animals. 7 th edition ; 379-486. Bailliere Tindall an imprint of Elsevier.

10. Tamura Y, Kawamura Y, Inoue I and Ishino S (2001) Scanning electron microscopy description of a new speciesofDemodex canis spp. Veterinary Dermatology. 12: 275-278.

11. Tamura Y, Moriyasu I, Kawamura Y and Ishino S (2000) A case of canine demodicosis complicated by Demodex canis and a short -bodied (unidentified) Demodex mite. Journal of the Japan Veterinary Medical Association. 53(10): 676-678. 